\title{
APRENDENDO A SER MENINA: PUBLICIDADE INFANTIL, GÊNERO E IDENTIDADE EM YOUTUBER MIRIM
}

\section{Learning to be a girl: child advertising, gender and identity in youtuber mirim}

\author{
Marcela Cristina Gomes da Silva - Universidade \\ Católica de Brasília /Brasil \\ Luciana da Silva Santos - Universidade Católica de Brasília /Brasil
}

\begin{abstract}
RESUMO: O presente trabalho pretendeu compreender como a identidade feminina, os estereótipos atrelados ao gênero e o incentivo ao consumo infantil são difundidos por e para as crianças por intermédio dos denominados vídeos unboxing divulgados por uma youtuber mirim. Para tanto, foi realizada a análise de conteúdo de três vídeos com conteúdo publicitário de brinquedos, que possibilitaram a construção de duas unidades temáticas: Discurso Publicitário e Ser menina. Os resultados apontaram para uma tendência à utilização de vídeos unboxing como forma de incentivar o consumo em crianças, utilizando-se de estratégias que pretendem aproximar o público infantil, youtuber mirim e a marca anunciada, além de se aproveitarem do senso crítico pouco desenvolvido da criança levando-a a acreditar em falsas promessas de felicidade e satisfação. Ademais, destaca-se que a publicidade contida na mídia digital carrega em si estereótipos que agem na construção da identidade feminina. Verificou-se que tais estereótipos disseminam o culto à beleza e à caracterização do feminino como sendo frágil, delicado, dócil e ingênuo ao utilizar a linguagem como forma de expressão de características que aludem exclusivamente ao gênero feminino. Identificados esses aspectos se faz importante, além das leis em vigor que visam à proteção da infância, à educação crítica das crianças e acompanhamento da família ao conteúdo exposto às mesmas, tendo em vista a formação de consumidores conscientes e os estereótipos de gênero que são incutidos no processo de subjetivação de cada indivíduo.
\end{abstract}

Palavras-chave: Consumo infantil. Estereótipos. Gênero. Subjetivação.

\begin{abstract}
The present work aimed to understand how feminine identity, gender stereotypes and the incentive to children consumption are disseminated to and through the children through the so-called unboxing videos released by a youtuber mirim. For that, a content analysis of three videos with advertising content of toys was carried out, which enabled the construction of two thematic units: Advertising Speech and Being a girl. The results pointed to a tendency to use unboxing videos as a way to encourage consumption in children, using strategies that aim to bring the child audience, youtuber mirim and the advertised brand, and take advantage of the child's poorly developed sense leading her to believe in false promises of happiness and satisfaction. In addition, it is emphasized that the advertising contained in the digital media carries within itself stereotypes that act in the construction of the feminine identity. It was verified that such stereotypes disseminate the cult of beauty and the characterization of the feminine as being fragile, delicate, docile and naïve when using language as a form of expression of characteristics that allude exclusively to the feminine gender. Once these aspects are identified, it is important, in addition to existing laws aimed at protecting children, critical education of children and monitoring of the family to the content exposed to them, with a view to the formation of conscious consumers and the gender stereotypes that are instilled in the process of subjectivities of each individual.
\end{abstract}

Educação, Psicologia e Interfaces, Volume 3, Dossiê Inclusão e Diversidade, p. 52-66, 2019. 
Aprendendo a ser menina: publicidade infantil, gênero e identidade em youtuber mirim

Keywords: Child Consumption. Gender. Stereotypes. Subjectivities.

\section{INTRODUÇÃO}

Na contemporaneidade a discussão da influência da mídia no desenvolvimento infantil tem se tornado gradativamente manifesta na relação entre infância e consumo (COUTO; DANTAS; REBOUÇAS, 2015). Essa relação é alvo de importantes debates no cenário nacional e internacional, além de ser problematizada por diferentes setores da sociedade, visto que a mídia tem se tornado cada vez mais presente na vida das crianças, que aprendem desde muito cedo a manipular a tecnologia que as cercam.

Segundo Buckingham (2007 apud TOMAZ, 2017, p. 13) "na virada do século XXI, as novas tecnologias permitiram que as crianças fossem não só consumidoras de bens materiais e simbólicos, mas também produtoras e emissoras". Tal fenômeno inconcebível em outras épocas só se tornou possível graças ao avanço das novas tecnologias. Nesse meio, o YouTube se destaca como uma das plataformas preferidas para se criar conteúdo online (OLIVEIRA, 2018). Essa preferência se dá pela possibilidade de criação e compartilhamento de conteúdo, além da interação contínua possibilitada na plataforma, essas ferramentas cativam as crianças que nessa geração estão muito mais envolvidas no ambiente virtual e tendo contato com as tecnologias de informação e comunicação do que nas gerações passadas.

No âmbito do YouTube, os youtubers mirins ${ }^{1}$ e os vídeos unboxing ${ }^{2}$ que são produzidos por eles são um fenômeno em destaque. Essas crianças chamam a atenção pela quantidade de marcas presentes nos conteúdos que produzem, sejam estas de brinquedos, empresas ou outros produtos (OLIVEIRA, 2018). Não obstante, as marcas presentes nessa esfera não são as únicas a chamar atenção, dado que muito mais do que a simples exibição de um produto, ou o estímulo ao consumo, à publicidade propicia difundir conceitos e ideias concebidas em meio à sociedade.

As dinâmicas presentes no consumo midiático afetam de maneira direta a construção da identidade infantil, especificamente no que abarca o gênero. Neste aspecto, figura em meio ao mercado e às indústrias culturais um discurso de estereótipos que representam as figuras de menina e mulher contribuindo para a formação de consciência e comportamentos (LISBOA; SILVA; REZENDE, 2015).

Visando um maior entendimento dessas questões, o presente estudo buscou compreender como a identidade feminina, os estereótipos de gênero e o estímulo ao consumo 
são difundidos por e para as crianças por meio de vídeos unboxing produzidos por youtuber mirim. Procurou-se assinalar a forma que o discurso da identidade feminina é disseminado através da publicidade de brinquedos no YouTube, identificar os elementos que caracterizam a estereotipização do gênero feminino na publicidade infantil da mídia digital, além de indicar os meios utilizados para difundir o estímulo ao consumo através da publicidade infantil contida no YouTube.

\section{METODOLOGIA}

O trabalho aqui proposto apresenta-se como de natureza qualitativa e dispõe-se a realizar uma análise descritiva e exploratória, a partir de vídeos unboxing com conteúdo publicitário de brinquedos divulgados no canal de uma youtuber mirim. À vista disso, objetiva verificar de que forma se constitui o conteúdo identitário e de estereótipos relacionados ao gênero feminino através do consumo no domínio do YouTube.

Para tanto, foram selecionados três vídeos unboxing com conteúdo publicitário de brinquedos dirigidos ao público feminino infantil e divulgados no canal homônimo de uma youtuber mirim. O canal escolhido é um dos mais visualizados e populares canais infantis do YouTube, protagonizado por uma adolescente de 13 anos considerada como uma das primeiras youtubers mirins do Brasil, e que começou a publicar vídeos com seis anos de idade (OLIVEIRA, 2018) e atualmente administra dois canais no YouTube (MARÔPO; SAMPAIO; MIRANDA, 2018).

Quanto à escolha pela categoria unboxing, esta foi realizada levando em consideração o constante crescimento dessa modalidade de vídeos na mídia digital. Dados da pesquisa “Geração YouTube: um mapeamento sobre o consumo e a produção infantil de vídeos para crianças de zero a 12 anos no Brasil, de 2015 a 2016", apontam que as categorias unboxing (975\%) e youtuber mirim (564\%) foram dentre os tipos de conteúdos produzidos e consumidos no YouTube por crianças as categorias que mais cresceram em audiência (ESPM MEDIA LAB, 2016 apud MARÔPO; SAMPAIO; MIRANDA, 2018, p.181).

Inicialmente foram levantadas as publicações realizadas no período de janeiro de 2018 a março de 2019, sendo esse período dividido em três categorias. Entre esse corpus foi contabilizado um ainda mais restrito, composto apenas por vídeos com conteúdo publicitário de brinquedos e classificados como unboxing, ou seja, publicações em que a protagonista do canal aparece abrindo caixas de brinquedos. O quadro abaixo apresenta a triagem realizada: 
Quadro 1- Levante do corpus

\begin{tabular}{|c|c|c|}
\hline Período analisado & Total de postagens & Total de vídeos unboxing \\
\hline Últimos 12 meses & 150 & 27 \\
\hline Últimos 7 meses & 71 & 7 \\
\hline Últimos 4 meses & 40 & 4 \\
\hline
\end{tabular}

Fonte: Elaborado pela autora

A partir da apuração realizada foram selecionados para composição do corpus os vídeos unboxing postados no período dos últimos 4 meses, conforme descrito abaixo:

Quadro 2- Vídeos selecionados para composição do corpus

\begin{tabular}{|l|c|c|}
\hline \multicolumn{1}{|c|}{ Nome do vídeo } & Duração & Data da postagem \\
\hline Abrindo boxy girls | Bonecas blogueiras & $12: 32$ & $07 / 12 / 2018$ \\
\hline $\begin{array}{l}\text { Hairdorables! Abrindo bonecas surpresa } \\
\text { (Super novidade) }\end{array}$ & $16: 47$ & $26 / 12 / 2018$ \\
\hline $\begin{array}{l}\text { Abrindo Hairdorable surpresa - Parte 02 } \\
\text { sbrindo squishy smashy mashy e } \\
\text { smooshy mushy }\end{array}$ & $7: 56$ & $28 / 12 / 2018$ \\
\hline
\end{tabular}

Fonte: Elaborado pela autora

É relevante pontuar que apesar de terem sido publicados quatro vídeos unboxing no período selecionado para composição do corpus, apenas três foram passíveis de análise, pois o vídeo denominado, "abrindo squishy smashy mashy e smooshy mushy” foi excluído do canal antes da realização da análise de dados desse trabalho.

A análise do corpus foi realizada centrada na análise de conteúdo proposta por Bardin (2002), a qual representa "um conjunto de técnicas de análise das comunicações visando obter, por procedimentos, sistemáticos e objetivos de descrição do conteúdo das mensagens indicadores (quantitativos ou não) que permitam a inferência de conhecimentos [...]" (BARDIN, 2002, p. 42).

Chizzotti (2017) pondera que seu objetivo é a compreensão crítica do sentido das comunicações em seu conteúdo e significado sejam estes manifestos ou latentes. "A análise de 
conteúdo absorve e cauciona o investigador por essa atração pelo escondido, o latente, o nãoaparente, o potencial de inédito (do não dito), retido por qualquer mensagem" (BARDIN, 2002, p. 9).

\section{RESULTADOS E DISCUSSÃO}

A seguir serão apresentados os dados referentes à análise de conteúdo realizada a partir dos objetivos a que se propõe esse trabalho. Tendo por base a análise de três vídeos foram produzidas duas Unidades Temáticas. Estas possibilitaram a construção de categorias, ambas obtidas após a transcrição dos vídeos, do corpus em estudo o qual perfez um total de 36 minutos e 35 segundos de gravação.

Foram utilizadas para composição das categorias palavras e/ou frases que melhor se adequaram a cada uma das Unidades Temáticas propostas, como será ilustrado mais adiante por meio de frases ditas pela Youtuber nos vídeos avaliados.

\subsection{Discurso publicitário}

Com base na transcrição e posterior decodificação do corpus foram obtidas três categorias, apresentas no quadro abaixo, conjuntamente com suas respectivas frequências absoluta e relativa de ocorrência:

Quadro 3- Categorias da Unidade Temática Discurso Publicitário

\begin{tabular}{|c|c|c|}
\hline \multicolumn{3}{|c|}{ DISCURSO PUBLICITÁRIO } \\
\hline Categorias & Frequência Absoluta & Frequência Relativa \\
\hline Exaltação do produto & & $43 \%$ \\
Emissão de valor pessoal & 46 & $37 \%$ \\
Interação com o público & 40 & $20 \%$ \\
& 21 & $100 \%$ \\
\hline Total & 107 & \\
\hline
\end{tabular}

Fonte: Elaborado pela autora

Na Unidade Temática Discurso publicitário foram contabilizadas 107 ocorrências. Na primeira categoria encontrada, nomeada de exaltação do produto, registraram-se as questões relativas à evidenciação das qualidades dos produtos apresentados. Dentre as 46 referências a esse aspecto enfatizam-se algumas: "Muito bacana, muito bacana mesmo!" "[...] Eu acho super legal." "Gente muito legal, que caixa incrível!" 
Aprendendo a ser menina: publicidade infantil, gênero e identidade em youtuber mirim

Variados são os artifícios utilizados para se convencer o consumidor das vantagens e qualidades de um produto. Nessa categoria é interessante observar o uso de um discurso monótono e repetitivo para destacar os atributos dos produtos exibidos.

Depreende-se que esta estratégia foi utilizada com o intuito de demonstrar para o público o quanto os brinquedos apresentados eram atrativos e proporcionadores de sentimentos agradáveis a quem os possui, ocasionando dessa forma o desejo por sua posse através de um discurso publicitário que induz claramente o consumo.

Deste modo, pelo fato de não ser capaz de fazer a separação entre fantasia e realidade, a criança tende a acreditar que os prazeres que caracterizam os anúncios realmente lhe serão ofertados, consequentemente demonstram maior abertura a persuasão e ao consumo do produto oferecido (INSTITUTO ALANA, 2009).

La Taille (2008) vai ao encontro dessa questão ao afirmar que a capacidade da criança de questionar e criticar as mensagens que lhes são passadas é inferior a do adulto, o que a torna suscetível a acreditar que aquilo de fato é como é apresentado, e que aquilo que afirmam ser sensacional realmente possui essa característica.

A autonomia intelectual e moral da criança só estarão completamente formadas após os 12 anos de idade por isso, antes dessa idade ela é considerada heterônoma. A sua não-autonomia a leva a acreditar nas afirmações provenientes de figuras de autoridade e prestígio. Essa tendência em seguir a outros é um marco no desenvolvimento da criança, que está iniciando sua inserção no mundo das regras e valores, dessa forma seguir "guias" torna-se necessário (LA TAILLE, 2008).

Com efeito, ao utilizar uma youtuber que possui grande prestígio em meio ao público infantil, a publicidade se aproveita do poder de influência exercido por ela sobre as demais crianças, tirando proveito dessa situação em benefício da marca que anuncia.

Outro aspecto observado na Unidade Temática Publicidade no Youtube foi à emissão de valor pessoal. Nessa segunda categoria, que obteve 40 alusões foram agrupados itens referentes à manifestação da opinião e/ou estado emocional da youtuber durante a abertura dos brinquedos apresentados. A exemplo: "Eu gostei muito dessas botas, elas são lindas." "Eu tô muito animada pra vê como que vai funcionar." "Gente eu acho que essa foi a melhor caixa que eu já recebi na minha vida."

Partindo do pressuposto de que a publicidade dirigida à criança utiliza-se de grande capacidade de identificação com as mesmas para influenciar suas escolhas a determinado 
produto (HENRIQUES, 2010) é notória nessa categoria a proposta de se estabelecer uma identificação entre youtuber e público infantil.

Quando publicam vídeos publicitários em seus canais os youtubers mirins passam a ter uma relação mais íntima com as marcas, transferindo esse imaginário para as crianças que os assistem (LEÃO et. al 2016). Essa aproximação entre marca, youtuber e público é realizada tendo em vista a criação de uma falsa familiaridade para que assim a divulgação do produto seja descaracterizada e não se apresente tal como a publicidade convencional que estamos habituados.

Esse tipo de estratégia atua de forma a estimular uma relação de confiança, criando uma ilusão de amizade. Nessa situação, a divulgação do produto passa a ser feita por um amigo e não mais por alguém distante, como é tido nas mídias tradicionais.

Essa tática é eficiente, sobretudo em crianças por serem muito influenciáveis por seus pares. Para Piaget (1999) a criança entre os 7 aos 12 anos se encontra no período das operações concretas, nessa fase começa a surgir o desejo de se vincular a um grupo, desse modo o grupo torna-se um referencial para a criança determinando seus comportamentos e preferencias.

$\mathrm{Na}$ última categoria dessa Unidade Temática intitulada Interação com o público, foram evidenciados os tópicos nos quais o público é convidado a interagir com o conteúdo apresentado. Apesar de estar presente apenas em $20 \%$ do material analisado. a interatividade se manifesta estrategicamente de forma a assegurar a aproximação com os espectadores. Como é demonstrado nos seguintes trechos: "Eu adorei e vocês?" "E eu quero saber, o que vocês acharam das boxing girls?" "Comentem aqui embaixo nos comentários."

A interatividade pode ser considerada uma estratégia midiática utilizada com o objetivo de promover proximidade e intimidade entre o youtuber e quem assiste ao conteúdo, tal artifício se assemelha ao encontrado na categoria anterior, por também se preocupar em aproximar marca e consumidor.

No conteúdo analisado, os espectadores eram solicitados a todo o momento a exprimirem suas preferências e pontos de vista além de curtir e comentar o material exibido. Esse aspecto é discutido por Leão e Pressler (2017) ao afirmarem que a interatividade é vista como uma chave para o sucesso.

Essa convocação à participação seduz as crianças que buscam muito mais do que apenas observar, a internet possibilita que elas discutam, questionem e opinem dando-lhes voz. A interação infantil com as mídias online é um processo ativo, no qual a criança que está por trás 
das câmeras não é a única a aparecer, mas também a criança que assiste, esta partilha suas opiniões através de comentários, curtidas e compartilhamentos (OLIVEIRA, 2018).

\subsection{Ser menina}

A análise do corpus desta Unidade Temática resultou em três categorias apresentadas no quadro 4, seguidas de suas respectivas frequências absoluta e relativa:

Quadro 4- Categorias da Unidade Temática Ser menina

\begin{tabular}{|c|c|c|}
\hline \multicolumn{3}{|c|}{ SER MENINA } \\
\hline Categorias & Frequência Absoluta & Frequência Relativa \\
\hline & 65 & $36 \%$ \\
Acessórios ditos femininos & 64 & $36 \%$ \\
Linguagem feminizada & 50 & $28 \%$ \\
Discurso infantilizado/diminuido & & \\
\hline Total & 179 & $100 \%$ \\
\hline
\end{tabular}

Fonte: Elaborado pela autora

Na Unidade Temática Ser menina foram sistematizadas 179 manifestações. A categoria acessórios ditos femininos agrupou os pontos referentes aos objetos pertencentes culturalmente ao gênero feminino. Foram encontradas 46 menções a essa categoria, conforme ilustrado abaixo: “[...] a gente pode abrir maquiagem, sapatos, bolsas e mais." "Sãos brincos. Olha que legal, eles são muito lindos e também veio um colar." "[...] também veio um batom, olha que fofura e um bracelete."

É interessante ressaltar que todos os vídeos componentes do corpus em análise faziam unboxing apenas de brinquedos voltados culturalmente ao público feminino, se limitando a apresentação de bonecas e seus utensílios, geralmente ligados à beleza, como roupas e maquiagens. É válida uma reflexão a respeito da reprodução desse modelo que impulsiona as meninas desde a infância a reproduzirem padrões que as compelem a buscar um ideal de beleza por meio do consumo. Como afirmam Couto, Stein e Martins (2016, p. 13):

Com o auxílio da publicidade, a linha tênue que separa o imaginário infantil do imaginário adulto está cada vez mais frágil, e quando tratamos do gênero feminino percebemos essa distância ainda menos longínqua, afinal desde a infância as meninas são apresentadas aos afazeres domésticos e aos cuidados com a beleza por meio de brinquedos que socialmente são intitulados "de menina". 
Essa imagem estereotipada de que à mulher cabe ser jovem, bela e magra é representativa da cultura do socialmente belo, que atua na formação da imagem publicitária do feminino impondo padrões a serem seguidos. Essas representações estão presentes desde a infância e agem na construção da identidade feminina.

Em geral, as campanhas publicitárias direcionadas às crianças, especialmente às meninas, trazem como tema a beleza. Estas são culturalmente ensinadas a buscá-la, cultivá-la e mantê-la desde cedo, sendo esta beleza alcançada por meio do consumo de produtos como maquiagens, roupas, sapatos e cosméticos. Nesse sentido a criança é induzida pela mídia em seus comportamentos, mesmo que não entenda do que se tratam os produtos que usa ou porque age de determinada maneira (NUNES; ARAÚJO, 2016).

A segunda categoria encontrada como caraterística da Unidade Temática Ser menina com 64 indicações foi titulada de linguagem feminizada. Nesse tópico encontram-se os elementos atribuídos à caracterização do feminino, tais como: "Gente é tudo muito bonitinho, muito carinhoso." "E aqui tem uma faixinha de cabelo com flores." "Ai ela é muito linda."

As frases acima reiteram o pensamento de Mota-Ribeiro (2003) ao confirmar que as imagens representativas da feminilidade que nos rodeiam concebem um discurso característico do que significa ser feminino na nossa sociedade, agindo na definição dessa feminilidade e acarretando em um processo que dita ao sexo feminino determinadas características e qualidades.

Constantemente o gênero feminino é caracterizado por adjetivos como frágil, carinhoso, delicado sempre em oposição ao gênero masculino que é definido por forte, grosseiro, corajoso. Tais diferenças de gênero se mostram notórias quando incorporadas em um linguajar tido como afeminado por utilizar expressões que caracterizam o feminino, demarcando desta forma a posição e as relações que a sociedade espera que sejam estabelecidas pelas meninas/mulheres.

A linguagem além de demonstrar relações, poderes e lugares, também as estabelece, servindo a sua divulgação, bem como produzindo e consolidando diferenças (LOURO, 2003). Neste sentido, é evidente o uso de um discurso atrelado a uma feminilidade caracterizada como frágil, delicada e dócil, que se utiliza de maneiras suaves e carinhosas de expressão.

Ao ser atingida por inúmeras narrativas a menina vai tomando conhecimento das características que se esperam dela pelo fato de ser menina, até que aos poucos ocorre naturalização e consolidação dos padrões como parte dos conhecimentos que a criança possui do seu próprio gênero (PIZZATTO, 2017). 
Aprendendo a ser menina: publicidade infantil, gênero e identidade em youtuber mirim

$\mathrm{Na}$ última categoria dessa Unidade Temática nomeada de Discurso infantilizado/diminuído foram reunidos os conteúdos que se apresentam no diminutivo, os quais totalizaram 50 evidências. A título de exemplo temos: "E aqui veio mais uma cartinha [...]" "[...] Tem várias caixinhas de compras." "Eu adoro mochilinhas."

Embora se avalie que a utilização do diminutivo se configure como uma estratégia de acesso ao público infantil problematiza-se aqui essa forma de expressão. Para Louro (2003) não é somente pelo ocultamento do feminino que a linguagem estabelece e delimita os lugares dos gêneros, o uso de diferentes adjetivos, diminutivos, verbos, analogias e associações também instauram lugares de poder e desigualdade.

O discurso disseminado pela mídia reforça os valores tradicionais que circulam em meio à sociedade favorecendo os estereótipos que caracterizam a mulher como vulnerável, indefesa, sexo frágil, entre outras características que posicionam o gênero feminino em um nível ínfero ao masculino, tais qualificações são naturalizadas e tidas por imutáveis pelos indivíduos, impregnando o imaginário infantil desde muito cedo.

De acordo com Projansky (2014, apud MARÔPO; SAMPAIO; MIRANDA, 2018, p. 177) "as meninas são alvo de forte espetacularização na cultura midiática contemporânea, que oscila entre a adoração e o desdém". Nesse seguimento, depreende-se desse tópico a tentativa de vincular a imagem da menina/mulher a um ser delicado e ingênuo, por meio de uma linguagem que nos remete a meiguice e à sensibilidade, características estas disseminadas como sendo exclusivas do gênero feminino.

Ainda que não seja o objetivo desse trabalho, é plausível pontuar que os conteúdos publicitários dirigidos ao público masculino infantil não fazem uso do diminutivo em seus discursos, este último frequentemente fica restrito apenas a publicidade de brinquedos ditos "de menina".

\section{CONSIDERAÇÕES FINAIS}

Todo esse processo entre youtubers mirins, vídeos unboxing e a publicidade implícita que os circunda ainda é muito recente. Partindo da necessidade de lançar um olhar mais aprofundado sobre esse fenômeno buscamos com esse estudo, identificar estereótipos de gênero difundidos na publicidade infantil, constatar como estes se relacionam à identidade feminina e apontar de que modo o estímulo ao consumo é empreendido, utilizando para esse fim vídeos unboxing direcinados ao público infantil. 
Partindo desses objetivos, o presente estudo concluiu que vídeos unboxing destinados às crianças englobam muito mais do que apenas desempacotar produtos e mostrar seus atributos, tendendo a ocultar a publicidade realizada e reforçar estereótipos difundidos em meio à sociedade.

Constatou-se que os vídeos analisados tendem a estimular de maneira oculta o consumo através do uso de artimanhas que visam transmitir um clima intimista e confiável por possibilitarem identificação e interação entre pares. Além disso, também relacionam a posse do produto à ideia de satisfação e alegria. Assim sendo, se aproveitam da inclinação que a criança possui de acreditar em tudo que lhes é apresentado, especialmente se feito por pessoas que admira ou em quem confia. Todos esses pormenores destinam-se a provocar na criança que assiste ao conteúdo o desejo de possuir o produto exibido.

Outra constatação possível permitiu depreender algumas asserções acerca da publicidade como reforçadora de estereótipos. Verificou-se, nos vídeos analisados, a existência de estereótipos de gênero, estes por meio da escolha da linguagem utilizada propagam o culto a beleza e a descrição do gênero feminino como frágil, delicado e inferior, estereótipos reproduzidos em meio à sociedade e que acompanham as meninas já na infância, colaborando para a construção de suas identidades.

Diante do que foi exposto, considera-se que os objetivos desse estudo foram alcançados visto que, a partir do levantamento bibliográfico correlato ao tema e sua posterior aplicação na análise do corpus foi possível, identificar estereótipos de gênero contidos nos vídeos, apreender como estes se relacionam à identidade feminina, além de identificar quais dispositivos manifestos nesse meio incentivam o consumismo.

Nesse cenário, a existência de leis que se propõem a proteger os infantes das influências da publicidade é de fato válida toda via, é necessário considerar que o consumo e suas facetas são elementos que caracterizam a sociedade em que estamos inseridos. Desta forma as crianças, mesmo com a proteção das leis, ainda serão submetidas a uma infinidade de recursos sedutores, logo se tornaram também consumidoras por isso, além da proteção é necessário também educar as futuras gerações para que aprendam a compreender, interpretar e criticar tudo aquilo que lhes é imposto e dessa forma possam vir a se tornar consumidores conscientes.

\section{Notas de rodapé}

${ }^{1}$ Youtubers mirins são crianças que produzem conteúdo para o YouTube (GERASIMCZUK; KARAGEORGIADIS, 2017). 
${ }^{2} \mathrm{O}$ termo unboxing se refere à gravação em vídeo da ação de desempacotar embalagens de produtos por parte dos usuários das redes sociais digitais, que narram esse processo de modo pessoal e detalhado (SATO, 2016).

\section{REFERÊNCIAS BIBLIOGRÁFICAS}

BARDIN, L. Análise de conteúdo. Lisboa: Edições 70, 2002.

CHIZZOTTI, A. Pesquisa em ciências humanas e sociais. 12 ed. São Paulo: Cortez, 2017. p. 98.

COUTO, J. ; DANTAS, T. ; REBOUÇAS, E. As pequenas mulheres da publicidade infantil. In: Congresso Brasileiro de Ciências da Comunicação, 38. 2015, Rio de Janeiro. Anais eletrônicos [...]. Rio de Janeiro: INTERCOM, 2015. Disponível em:

http://portalintercom.org.br/anais/nacional2015/resumos/R10-0518-1.pdf. Acesso em: 26 out. 2018.

COUTO, J. ; STEIN, R. ; MARTINS, M. A necessidade de um ensino crítico da mídia: o gênero feminino e os estereótipos difundidos pela publicidade. In: Congresso Brasileiro de Ciências da Comunicação, 39. 2016, São Paulo. Anais eletrônicos [...]. São Paulo: INTERCOM, 2016. Disponível em: http://portalintercom.org.br/anais/nacional2016/resumos/R11-0180-1.pdf. Acesso em: 26 out. 2018.

GERASIMCZUK, L.; KARAGEORGIADIS, E. Publicidade dirigida a criança na rede: ilegalidades nos canais de youtubers mirins. In: Comitê Gestor da Internet no Brasil. Tic kids online Brasil: pesquisa sobre o uso da internet por crianças e adolescentes no Brasil 2016. São Paulo: [s.n.], 2017. p. 39-46. Disponível em:

https://cetic.br/media/docs/publicacoes/2/TIC_KIDS_ONLINE_2016_LivroEletronico.pdf. Acesso em: 18 out. 2018.

HENRIQUES, I. Controle social e regulação da publicidade infantil: O caso da comunicação mercadológica de alimentos voltada às crianças brasileiras. Revista Eletrônica de

Comunicação, Informação e Inovação em Saúde, Rio de janeiro, v. 4, n. 4, p. 72-84, nov. 2010. Disponível em: https://www.reciis.icict.fiocruz.br/index.php/reciis/article/view/649.

Acesso em: 18 out. 2018.

INSTITUTO ALANA. Projeto Criança e Consumo. Por que a publicidade faz mal para as crianças. 2. ed. [São Paulo], 2009. Disponível em: http://criancaeconsumo.org.br/wpcontent/uploads/2014/02/por-que-a-publicidade-faz-mal-para-as-criancas.pdf. Acesso em: 19 out. 2018.

\section{LA TAILLE, Y. Contribuição da Psicologia para o fim da publicidade dirigida à} criança. Brasília: Conselho Federal de Psicologia, 2008. Disponível em:

https://site.cfp.org.br/wp-content/uploads/2008/10/cartilha_publicidade_infantil.pdf. Acesso em: 17 out. 2018.

LEÃO, D. et. al . A CiberPublicidade Infantil : experiência, linguagem e consumo. In: Congresso Brasileiro de Ciências da Comunicação, 39., 2016, São Paulo. Anais eletrônicos 
[...]. São Paulo: INTERCOM, 2016. Disponível em:

http://portalintercom.org.br/anais/nacional2016/resumos/R11-2130-1.pdf. Acesso em: 26 out. 2018.

LEÃO, D. ; PRESSLER, N. Youtuber mirim e o consumo infantil. In: Congresso Brasileiro de Ciências da Comunicação, 40. , 2017, Curitiba. Anais eletrônicos [...]. Curitiba:

INTERCOM, 2017. Disponível em:

http://portalintercom.org.br/anais/nacional2017/resumos/R12-2925-1.pdf. Acesso em: 05 maio 2019.

LISBOA, W. ; SILVA T. ; REZENDE, A. Magia é de menina, aventura é de menino: os binarismos de gênero na infância pela perspectiva da indústria cultural. Vozes e Diálogo, Itajaí, v. 14, n. 02, p. 86-98, jul./dez. 2015. Disponível em:

https://siaiap32.univali.br/seer/index.php/vd/article/view/8183. Acesso em: 18 out. 2018.

LOURO, G. Gênero, sexualidade e educação: uma perspectiva pós- estruturalista. 6. ed. Petrópolis: Vozes, 2003.

MARÔPO, L.; SAMPAIO, I.; MIRANDA, N. Meninas no YouTube: participação, celebrização e cultura do consumo. Estudos em Comunicação, Setúbal, v. 1, n. 26, p.175195, maio 2018. Disponível em: http://ojs.labcomifp.ubi.pt/index.php/ec/article/view/402/pdf. Acesso em: 15 out. 2018.

MOTA-RIBEIRO, S. Corpos visuais - imagens do feminino na publicidade. In: MACEDO, A. ; GROSSEGESSE, O. (org.). Representações do corpo. Braga: Centro de Estudos Humanísticos da Universidade do Minho, 2003. p. 115-132.

NUNES, M. ; ARAÚJO, N. A exposição infantil em vídeos de beleza: erotização da infância em favor do consumismo. Temática, [Paraíba], v.12, n. 04, p. 168 -182, abr. 2016.

Disponível em: http://periodicos.ufpb.br/ojs2/index.php/tematica. Acesso em: 05 maio 2019.

OLIVEIRA, J. Comunicação, consumo e infância na era das mídias on-line: uma análise sobre a publicidade infantil nos vídeos da youtuber mirim Julia Silva. 2018. Dissertação (Mestrado em Comunicação Social) - Universidade Metodista de São Paulo, São Bernardo do Campo, 2018. Disponível em: http://tede.metodista.br/jspui/handle/tede/1765. Acesso em: 17 out. 2018.

PIAGET, J. A linguagem e o pensamento da criança. 7. ed. São Paulo: Martins Fontes, 1999.

PIZZATTO, B. Aprendendo a ser menina: a publicidade como parte do processo de construção da identidade de gênero. 2017. Trabalho de Conclusão de Curso (Graduação em Comunicação Social) - Universidade Federal do Rio Grande do Sul, Porto Alegre, 2017.

Disponível em: https://www.lume.ufrgs.br/handle/10183/177710. Acesso em: 05 maio 2019.

SATO, S. Abrindo a embalagem na rede: reflexões sobre o consumo e cultura digital a partir dos unboxings vídeos. In: Congresso Internacional Comunicação e Consumo, 2016, São Paulo. Anais eletrônicos [...]. São Paulo: COMUNICOM, 2016. Disponível em: 
https://www.researchgate.net/profile/Silvio_Sato/publication/309187054_Abrindo_a_embalag em_na_rede_reflexoes_sobre_consumo_e_cultura_digital_a_partir_dos_unboxing_videos_1/li nks/58037d3108ae310e0d9f396c.pdf. Acesso em: 25 out. 2018.

TOMAZ, R. As redes sociais digitais como campo de pesquisa da infância e o caso das youtubers mirins. In: Comitê Gestor da Internet no Brasil. Tic kids online Brasil: pesquisa sobre o uso da internet por crianças e adolescentes no Brasil 2016. São Paulo: [s.n.], 2017. p. 47-52. Disponível em: https://cetic.br/media/docs/publicacoes/2/TIC_KIDS_ONLINE_2016_LivroEletronico.pdf. Acesso em: 18 out. 2018.

\section{Credenciais das autoras}

SILVA, Marcela Cristina Gomes da. Graduanda do curso de Psicologia da Universidade Católica de Brasília. E-mail: marcelacristina.gomesdasilva@gmail.com

SANTOS, Luciana da Silva. Docente do curso de Pós-Graduação Stricto Sensu em Psicologia da Universidade Católica de Brasília, Doutora em Psicologia Clínica e Cultura pela Universidade de Brasília (UNB). E-mail: lucianasantospsi@gmail.com

Endereço para correspondência: Marcela Cristina Gomes da Silva. QS 07 Lote 01 EPCTTaguatinga, CEP: 71966-700, Brasília/DF. E-mail: marcelacristina.gomesdasilva@gmail.com

Como citar este artigo (Formato ABNT): SILVA, Marcela Cristina Gomes da; SANTOS, Luciana da Silva. Aprendendo a ser menina: publicidade infantil, gênero e identidade em youtuber mirim. Educação, Psicologia e Interfaces, v. 3, Dossiê Inclusão e Diversidade, p. 52-66, 2019. DOI: https://doi.org/10.37444/issn-2594-5343.v3i4.176

Recebido: 03/10/2019.

Aceito: 20/11/2019. 